\title{
Dynamic changes in moisture content and applicability analysis of a typical litter prediction model in Yunnan Province
}

\author{
Yunlin Zhang ${ }^{\text {Corresp., } 1}$, Lingling Tian ${ }^{1}$ \\ ${ }^{1}$ School of Biological Sciences, Guizhou Education University, Guiyang, Asian, China \\ Corresponding Author: Yunlin Zhang \\ Email address: zhangyunlin@gznc.edu.cn
}

Background: Forest fire risk predictions are based on the most conservation daily predictions, and the lowest litter moisture content of each day is often used to predict the day's fire risk. Yunnan Province is the area with the most frequent and serious forest fires in China, but there is almost no research on the dynamic changes and model predictions of the litter moisture content in this area. Therefore, to reduce the occurrence of forest fires and improve the accuracy of forest fire risk predictions, it is necessary to understand these dynamic changes and establish an appropriate prediction model for the typical litter moisture content in Yunnan Province.

Method: During the fire prevention period, daily dynamic changes in the litter moisture content are obtained by monitoring the daily step size, and the relationships between the litter moisture content and meteorological elements are analyzed. In this study, the meteorological element regression method, moisture code method and direction estimation method are selected to establish litter moisture content prediction models, and the applicability of each model is analyzed.

Results: We found that dynamic changes in the litter moisture content have obvious lags compared with meteorological elements, and the litter moisture content is mainly related to the air temperature, relative humidity and wind speed. With an increase in the sampling interval of meteorological elements, the significances of these correlations first increase and then decrease. The moisture content value obtained by directly using the moisture code method in the Fire Weather Index (FWI) significantly different from the measured value, so this method is not applicable. The mean absolute error (MAE) and mean relative error (MRE) values obtained with the meteorological element regression method are $2.97 \%$ and $14.06 \%$, those from the moisture code method are $3.27 \%$ and $14.07 \%$, and those from the direct estimation method are $2.82 \%$ and $12.76 \%$, respectively.

Conclusions: The direct estimation method has the lowest error and the strongest extrapolation ability; this method can meet the needs of daily fire forecasting. Therefore, it is feasible to use the direct estimation method to predict litter moisture contents in Yunnan Province. 
1 Dynamic changes in moisture content and

2 applicability analysis of a typical litter prediction

3 model in Yunnan Province

4

5

6

7

8

9

10

11

12

13

14

15

16

17

Yunlin Zhang ${ }^{1}$, Lingling $\operatorname{Tian}^{1}$

${ }^{1}$ School of Biological Sciences, Guizhou Education University, Guiyang, Guizhou, China

Corresponding Author:

Yunlin Zhang ${ }^{1}$

Gaoxin St. 115, Guiyang, Guizhou, 550018, China

Email address: zhangyunlin@gznc.edu.cn

\section{Abstract}

Background: Forest fire risk predictions are based on the most conservation daily predictions, and the lowest litter moisture content of each day is often used to predict the day's fire risk. Yunnan Province is the area with the most frequent and serious forest fires in China, but there is almost no research on the dynamic changes and model predictions of the litter moisture content in this area. Therefore, to reduce the occurrence of forest fires and improve the accuracy of forest fire risk predictions, it is necessary to understand these dynamic changes and establish an appropriate prediction model for the typical litter moisture content in Yunnan Province.

Method: During the fire prevention period, daily dynamic changes in the litter moisture content are obtained by monitoring the daily step size, and the relationships between the litter moisture content and meteorological elements are analyzed. In this study, the meteorological element regression method, moisture code method and direction estimation method are selected to establish litter moisture content prediction models, and the applicability of each model is analyzed.

Results: We found that dynamic changes in the litter moisture content have obvious lags compared with meteorological elements, and the litter moisture content is mainly related to the air temperature, relative humidity and wind speed. With an increase in the sampling interval of meteorological elements, the significances of these correlations first increase and then decrease. The moisture content value obtained by directly using the moisture code method in the Fire Weather Index (FWI) significantly different from the measured value, so this method is not applicable. The mean absolute error (MAE) and mean relative error (MRE) values obtained with the meteorological element regression method are $2.97 \%$ and $14.06 \%$, those from the moisture code method are $3.27 \%$ and $14.07 \%$, and those from the direct estimation method are $2.82 \%$ and $12.76 \%$, respectively. 
40 Conclusions: The direct estimation method has the lowest error and the strongest extrapolation

ability; this method can meet the needs of daily fire forecasting. Therefore, it is feasible to use the direct estimation method to predict litter moisture contents in Yunnan Province.

\section{Introduction}

The litter moisture content (LMC) represents the internal water content of litter and directly affects the difficulty with which litter is ignited as well as a series of fire behavior indicators after a fire occurs; accurate LMC values are of great significance for assessing forest fire risk (Deeming, 1976; Bradshaw et al., 1984; Chuvieco, et al., 2004). The LMCs obtained by the drying method are the most accurate, but this method requires the drying of litter, so it cannot be used to obtain instantaneous LMCs and cannot be applied in practice (Jin and Chen, 2012). Therefore, it is necessary to determine the dynamic changes that occur in the LMC, analyze its influencing factors, and seek a high-precision LMC prediction method for use in forest fire risk predictions.

Yunnan Province is a high-incidence area of forest fires in China. According to statistics, there were 6410 forest fires in the region in 2001-2017, accounting for approximately $20 \%$ of the number of forest fires in Southwest China, with an average annual burned area of 150000 ha (Zhang, et al., 2021). However, few studies have been conducted on the LMC in this area, and the dynamic changes that occur in different types of LMCs respond differently to the environment (Byram and Jemison, 1943; Anderson et al., 1978; Wagner, 1979; Pech, 1990; Holden and Jolly, 2012). Understanding the dynamic changes that occur in the typical litter moisture content in Yunnan Province during the fire prevention period and obtaining an LMC prediction model with a high accuracy and strong extrapolation ability are of great significance.

At present, LMC prediction methods mainly include remote sensing estimations, meteorological element regression methods, semiphysical methods and process-based methods. Among them, remote sensing estimation methods are suitable for large-scale LMC research; but its moisture content is calculated through the model obtained by ground monitoring moisture content, with the change of climate area, terrain and vegetation type, the accuracy of the method will be affected. Therefore, this method depends on the prediction model obtained by ground monitoring moisture content to a certain extent. (Toomey and Vierling, 2005; Nolan et al., 2016). Process-based methods can reveal the dynamic change mechanisms of litter water, and the prediction effects of these methods are the best. However, due to the complexity of processbased models and the numerous required parameters, it is difficult to apply these methods in practice (Matthews, 2006). Meteorological element regression methods predict the LMC by establishing correlations between the LMC and meteorological elements. These methods are simple, but because the dynamic changes in LMC have significant spatial heterogeneity, these methods have poor extrapolation abilities, and considerable manpower and material resource costs would be required to popularize these methods (Pook and Gill, 1993; Ruiz et al., 2002). The semiphysical methods take physical models as their main equations, but in the semiphysical methods, some of the parameters are obtained by statistical methods. With simple research 
80

81

82

83

84

85

86

87

88

89

90

91

92

93

94

95

96

97

98

99

100

101

102

103

104

105

106

107

108

109

110

111

112

113

114

115

116

117

118

methods and strong extrapolation abilities, semiphysical methods share the advantages of both the physical methods and statistical methods (Kandya et al., 1998; Slijepcevic et al., 2013).

Meteorological element regression methods and semiphysical methods are the two most widely used method types (Zhang and Sun, 2020). In particular, for the litter types in specific areas, as a simple statistical method, the meteorological element regression method is simple and practicable, and the prediction accuracy may higher than the simephysical method or processbased method to a certain extent (Matthews et al., 2010; Sun et al., 2015). However, for the prediction model of LMC in Yunnan, the meteorological element regression method has not been studied systematically, so it needs to be analyzed. Therefore, these two methods are selected in this study to analyze the prediction effect of the LMC.

The direct estimation method is the most widely used method among semiphysical methods; this method was proposed by Catchpole (2001). It mainly takes the water vapor exchange equation as the main body, and the parameters are obtained through experiments. In addition, the fine fuel moisture code in the Canadian Fire Risk Rating System reflects the dryness of litters; this code also adopts a semiphysical method, has a good extrapolation ability, and is widely used in globally (Viney and Hotton, 1989; Wotton and Beverly, 2007; Anderson and Aderson, 2009). However, because its parameters are obtained from jack pine and lodgepole pine in Canada, whether it is suitable for the typical litter in Yunnan Province still needs to be verified.

Research shows that the LMC monitoring step size has a certain impact on the accuracy of a prediction model, and shortening the step size will improve the LMC prediction accuracy (Sun et al., 2015; Zhang and Sun, 2020). However, for this study, the main purpose was to apply prediction models to obtain forest fire risk predictions, and forest fire risk predictions are based on the most conservation LMC predictions, which are usually published once a day.

Understanding the daily dynamic changes in the LMC is usually the most important concern of forest fire managers and researchers (Zhang, 2018). Therefore, in this study, the dynamic changes in the LMC were analyzed with a daily step size.

\section{Materials \& Methods}

\section{Overview of the study area}

The study area is located in Jindian Forest Park $\left(25^{\circ} 05^{\prime} 55^{\prime \prime} \mathrm{N}, 102^{\circ} 50^{\prime} 3^{\prime \prime} \mathrm{E}\right)$, Kunming City, Yunnan Province, the overview map of the study area is shown in Figure 1. This area belongs to the central part of the Yunnan-Guizhou Plateau in China, with an elevation of approximately $1890 \mathrm{~m}$. It is adjacent to Dianchi Lake in the south and is surrounded by mountains on the other three sides. The study area has a low-latitude, subtropical plateau mountain climate with an average annual temperature of approximately $15^{\circ} \mathrm{C}$, high solar radiation, obvious dry season and rainy season distributions, and an average annual precipitation of approximately $1800 \mathrm{~mm}$, with precipitation mainly concentrated from June to October. The common trees in the study area include Pinus yunnanensis, which accounts for approximately $70 \%$ of the forest area in this region, Pinus armandii, Platycladus orientalis, Cyclobalanopsis glaucoides and Quercus 
119 acutissima. The main shrubs are Myrica rubra and Camellia pitardii. The fire prevention period

120 in the study area lasts from December 1 of the current year to June 15 of the next year.

\section{Sample plot setting}

122 The typical forest types in the study area mainly include Pinus yunnanensis forests, Pinus

123

124

125

126

127

128

129

130

131

132

133

134

135

136

137

138

139

140

141

142

143

144

145

146

147

148

149

150

151

152

153

154

155

156

157 armandii forests and Platycladus orientalis forests, and the slope, aspect and canopy density have significant effects on dynamic changes in the LMC (Holden and Jolly, 2012). Therefore, according to different slopes, aspects and canopy densities, this study selected Pinus yunnanensis forests, Pinus armandii forests, Platycladus orientalis forests and Pinus yunnanensis-Pinus armandii mixed forests as the research objects and selected eight forest stands with different aspects and slope positions for analysis. Among them, the forest type with distribution area are Pinus armandii, Pinus yunnanensis, Pinus yunnanensis-Pinus armandii mixed and Platycladus orientalis from high to low. Therefore, the number, slope and position of the stands are determined according to the area and location of the distribution. The stand is selected to reflect the actual research situation as much as possible, so it is selected randomly, and the thickness of fuelbed is also different.

Sample plots of $20 \mathrm{~m} \times 20 \mathrm{~m}$ were set in each stand, the basic information and overview map of the stands is shown in Table 1 and Figure 1 respectively. A total of 8 samples plots are set, including 2, 3, 1 and 2 sample plots respectively for the forest stand of Pinus yunnanensis, Pinus armandii, Platycladus orientalis and Pinus yunnanensis-Pinus armandii mixed. The monitoring time of the moisture content of the litters was 100 days, from February 10 to May 29, 2014.

\section{Monitoring the litter moisture content}

In this study, only the leaves of litter on the surface were analyzed. Destructive sampling and weighting after drying is the LMC monitoring method that provides the closest estimation to the true value. Therefore, destructive sampling was selected in this study (Zhang, 2018). To prevent forest edge effects, all plots were set within areas 5-15 $\mathrm{m}$ from the forest edges. The main purpose of the daily LMC monitoring in this study is for applications in fire risk prediction; these prediction methods are based on the most conservative daily prediction. Therefore, the lowest daily LMC value (at 14:00) is selected for monitoring. During daily monitoring, 3 sampling points were randomly selected in each plot, and approximately $50 \mathrm{~g}$ litter was collected from each sampling point. The litter samples were put into envelopes and weighed immediately. The fresh weights were recorded, and then the samples were brought back to the laboratory. The litter was dried at $105^{\circ} \mathrm{C}$ until the weight no longer changed, and this final weight was recorded as the dry weight. In the case of rainfall, the free water on the surface of the litter was wiped off with absorbent paper, and sealing pockets were placed in the envelopes to prevent the litter samples from wetting each other on the way back to the laboratory, as this would have affected the LMC determination results. The average daily LMC value of the three sample points in each plot was taken as the LMC value of the sample plot. The LMC calculation formula of each sample point is shown in equation (1):

$$
M=\frac{W_{H}-W_{D}}{W_{D}} \times 100
$$


158

159

160

161

162

163

164

165

166

167

168

169

170

171

172

173

174

175

176

177

178

179

180

181

182

183

184

185

186

187

188

189

190

191

192

193

194

195

196

where $\mathrm{M}$ represents the $\mathrm{LMC}$ value (\%); $W_{H}$ represents the wet weight of the litter (g); and $W_{D}$ represents the dry weight of the litter $(\mathrm{g})$.

\section{Monitoring meteorological elements}

Appropriate locations were selected in the study area, and HOBO Weather Stations (U30-2, Onset Company, US) were set up $1.5 \mathrm{~m}$ from the ground to monitor meteorological elements in the study area. The meteorological stations recorded meteorological elements such as the air temperature, relative humidity, wind speed and rainfall with a step length of $30 \mathrm{~min}$. The monitoring time was earlier than the LMC monitoring time and was synchronized with the sampling time.

The basic meteorological element conditions in the study period are shown in Table 2. During the study period, the daily average air temperature was $22.74{ }^{\circ} \mathrm{C}$, the highest and lowest daily air temperature was $32.33{ }^{\circ} \mathrm{C}$ and $8.77^{\circ} \mathrm{C}$, respectively. The variation range of daily relative humidity was $14.7 \%-92.3 \%$, the daily average relative humidity was $37.18 \%$, and the daily relative humidity in half of the days during the monitoring period is lower than $31.30 \%$. In addition, during the monitoring period, the daily average wind speed was $2.78 \mathrm{~m}^{-1} \mathrm{~s}^{-1}$, the variation range of the wind speed was $0.00 \mathrm{~m} \cdot \mathrm{s}^{-1}-9.97 \mathrm{~m} \cdot \mathrm{s}^{-1}$, the daily maximum accumulate rainfall was $42.81 \mathrm{~mm}$, and the daily average rainfall in rainfall days was $1.34 \mathrm{~mm}$.

\section{Model description- Multiple regression method of meteorological element}

Dynamic changes in the LMC are mainly affected by the air temperature, relative humidity, wind speed and rainfall (Glahn and Ruth 2003; Anon 2012.). The increase of air temperature will improve the ability of air to carry moisture, which will increase the saturation humidity and decrease the relative humidity, the moisture of the litter will diffuse outward, and the LMC will decrease (Alves et al., 2009). The wind speed will accelerate the moisture diffusion of the litter and reduce the temperature of the litter, and also affect the dynamic change of LMC (Fiorucci et al., 2008; Zhang et al., 2018). In addition, rainfall will significantly increase litter moisture (Wotton, 2009). Other meteorological elements will also affect the dynamic changes of LMC, such as cloud, solar radiation and soil moisture content, but these elements have less and indirect impact on dynamic change of LMC than temperature, humidity, wind speed and rainfall (Matthews, 2014). Therefore, only these elements are selected in this study. And the responses of the LMC to these elements have certain lags (Zhang and Sun, 2020). Therefore, this study takes 14:00 as the node to calculate each average meteorological element $n$ days ago (except for rainfall, for which the accumulation at $\mathrm{n}$ days before rainfall was measured), which was recorded as $M_{-n}(M$ is air temperature, relative humidity, wind speed or rainfall, expressed by $\mathrm{T}, \mathrm{H}, \mathrm{W}$ and $\mathrm{R}$, respectively; $\mathrm{n}$ is $0-10$.).

The LMC was taken as the dependent variable, and $M_{-n}$ was taken as the independent variable. The stepwise regression method was selected to obtain the appropriate predictors. The stepwise regression method is selected because it is a regression analysis method to establish the optimal regression equation. Since it introduces a new independent variable, it is necessary to 
197

198

199

200

201

202

203

204

205

206

207

208

209

210

211

212

213

214

215

216

217

218

219

220

221

222

223

224

225

226

227

228

229

230

231

232

233

test the old independent variables one by one, and eliminate the independent variables that are not significant in the partial regression sum of squares, so that they are introduced and eliminated until neither new variable are introduced nor old variables are deleted. After this step, the 'optimum' multiple linear regression equation is obtained, and the remaining independent variables are both important and there is no serious multicollinearity (Zhang, 2018). The model form of the regression method used for the meteorological elements is shown in equation (2):

$$
M=b_{0}+\sum_{\mathrm{i}=0}^{10} X_{i} b_{i}
$$

where $M$ represents the LMC value; $b_{0}$ represents the prediction model constant; $X_{i}$ represents the meteorological element selected in the equation; and $b_{i}$ represents the coefficient.

\section{Model description- Direct estimation method}

The direct estimation method, proposed by Catchpole, is based on the equilibrium moisture content and directly uses the moisture content data of the previous day and meteorological data to predict the LMC (Catchpole, 2001). The main equation of this method is carried out by the water diffusion equation proposed by Byram in 1963 (Byram and Nelson, 1963), and the equation form is shown in equation (3):

$$
\frac{d m}{d t}=\frac{M-E}{\tau}
$$

where $d m$ represents the value of the change in the LMC; $d t$ represents the time interval (h); $M$ represents the LMC value; $E$ represents the equilibrium moisture content; and $\tau$ represents the time lag (h).

The equilibrium moisture content models mainly include the Nelson model (Nelson and Ralph, 1984), Simard model (Simard et al., 1968), Van Wagner model (Wagner, 1977), etc.; compared with other equilibrium moisture models, the Nelson model is a semiphysical model that is based on the Gibbs equation, which has the advantages of both physical method and statistical method. The method is simple and has good extrapolation effect, and it is the most widely used. Therefore, in equation (3) of this study, the Nelson model is selected as the equilibrium moisture content model, and the model form is shown in equation (4):

$$
E=\alpha+\beta \log \left(-\frac{R T}{m} \log H\right)
$$

where $R$ represents the universality constant, $8.314 \mathrm{~J} \cdot \mathrm{K}^{-1} \cdot \mathrm{mol}^{-1} ; T$ represents the air temperature (K); $m$ represents the atomic mass of water molecules, $18.0153 \mathrm{~g} \cdot \mathrm{mol}^{-1} ; H$ represents the relative humidity (\%); and $\alpha$ and $\beta$ represent the parameters to be estimated.

In the direct estimation method, the time lag of litter must be fixed, and this study is carried out using a daily time step, so $\Delta t=24 h$. By discretizing equation (3), the discretized water diffusion equation expressed in equation (5) is obtained:

$$
M_{i}=\lambda^{2} M_{i-1}+\lambda(1-\lambda) E_{i-1}+(1-\lambda) E_{i}
$$

where $M_{i}$ and $M_{i-1}$ represent the moisture content of the current day and the previous day (\%), respectively; $E_{i}$ and $E_{i-1}$ represent the equilibrium moisture content of the current day and the previous day (\%), respectively; and $\lambda$ represents the parameter to be evaluated in the model. 
234

235

236

237

238

239

240

241

242

243

244

245

246

247

248

249

250

251

252

253

254

255

256

257

258

259

260

261

262

263

264

265

266

267

268

269

270

271

According to equation (4), the daily equilibrium moisture content is obtained in equation (5), the nonlinear estimation is carried out with the objective of minimizing the square sum of the measured and predicted LMC values, and the parameters $\lambda, \alpha$ and $\beta$ are obtained.

\section{Model description- Moisture code method}

The fine fuel moisture code (FFMC) in the fire weather index (FWI) represents the moisture content of fine fuel with a surface thickness of $1.2 \mathrm{~cm}$ and a load of $0.25 \mathrm{~kg} \cdot \mathrm{m}^{-2}$; this value characterize the humidity of litter to a certain extent. The scale model is mainly used to convert values between the LMC and moisture code. At present, the FF scale model is the most commonly used model (Wagner, 1987), as shown in equation (6):

$$
M_{F F}=147.27 \frac{(101-F)}{(59.5+F)}
$$

where $M_{F F}$ represents the predicted value of moisture content (\%) and $F$ represents the FFMC value, which is the same as that described below.

In addition, since the study area is a dry and hot area during the fire prevention period, this study also adds an FX scale model that is suitable for dry and hot areas (Lawson et al., 1996), as shown in equation (7).

$$
M_{F X}=32.87 \frac{(101-F)}{(13.28+F)}
$$

$M_{F F}$ and $M_{F X}$ were compared with the measured LMC values to explore whether the direct scale model used was applicable for predicting moisture contents in this area. If it was not applicable, we would try to establish a correlation between the measured LMC value and the predicted $M_{F F}\left(M_{F X}\right)$ value and analyze the prediction effect of the model. Due to the large moisture content dataset, the variation in this series was larger than that in the predicted values; the natural logarithm was used to transform the data to realize variance uniformity. Then, a simple linear relationship was established between the measured values and the predicted values after the data was transformed (Wotton and Beverly, 2007), and an LMC regression prediction model was obtained based on the moisture code. This model was recorded as the moisture code regression model, and the model form is shown in equation (8):

$$
M=\alpha M_{F F(F X)}^{\beta}
$$

where $M$ represents the measured LMC value (\%); $M_{F F / F X}$ represents the moisture content values predicted based on the FF or FX scale models; and $\alpha$ and $\beta$ represent the parameters to be estimated.

\section{Statistical analysis}

Data process It is generally believed that when the LMC value is higher than $35 \%$, it is difficult for forest fires to occur (Luke and Mcarthur, 1978). Therefore, this study mainly carried out data analysis when the LMC value was lower than $35 \%$. The basic statistics of the LMC data of eight sample plots were obtained, including the minimum value, maximum value, average value and other indicators.-

Correlation analysis According to the meteorological data $M_{-n}$ sorted in section Model description- Multiple regression method of meteorological element , the Spearman method 
272 was used to analyze the correlations between the LMC and meteorological elements. Taking the 273 time series as the abscissa and each correlation coefficient as the ordinate, broken line charts of 274 the correlation coefficients of eight typical LMC dynamic changes and meteorological elements 275 with time were given.

276 Model accuracy analysis The FF and FX scale models were directly used to obtain the 277 predicted LMC values, $t$-tests were performed with the measured values to analyze whether 278 significant differences existed, and the average absolute error (MAE), relative average error 279 (MRE) and root mean square error (RMSE) of the prediction model were calculated. The 280 specific equations are shown as (9)-(11), and the suitability of directly using FF and FX scale 281 models to predict the LMC was analyzed:

282

283

284

285

286

287

288

289

290

291

292

293

294

295

296

297

298

299

300

301

302

303

304

305

306

307

308

309

$$
\begin{gathered}
M A E=\frac{1}{n} \sum_{i=1}^{n}\left|M_{i}-M_{j}\right| \\
M R E=\frac{1}{n} \sum_{i}^{n} \frac{\left|M_{i}-M_{j}\right|}{M_{i}} \times 100 \% \\
R M S E=\sqrt{\frac{1}{n} \sum_{1}^{n}\left(M_{i}-M_{j}\right)^{2}}
\end{gathered}
$$

where $M_{i}$ represents the measured LMC value (\%) and $M_{j}$ represents the predicted LMC value $(\%)$.

For all LMC prediction models established in this research, $\mathrm{N}$-fold cross-validation was selected to test the model accuracies, the model errors were calculated according to equations (9)-(11), and the prediction accuracy of the LMC prediction model was compared.

Taking the monitoring time as the abscissa and the measured and predicted values from the multiple regression method of meteorological element, the direct estimation method and the moisture content method as the ordinate, the dynamic changes in the moisture content during the study period were drawn, and the different changes in the LMC predicted by the three methods were compared. Since this study only analyzes the data with LMC below $35 \%$, and the abscissa is the whole research time, the line segment of the figure will be discontinuous. In addition, taking the measured value as the abscissa and the predicted values from the three prediction methods as the ordinate, a curve was fit, and a 1:1 line was drawn to compare the prediction effects of the three methods in different LMC intervals.

Model extrapolation comparison The three LMC prediction models were obtained for eight plots, and the prediction methods were substituted into the remaining seven plots to obtain the prediction errors of the plot models when extrapolated to other plots. The minimum, maximum, mean and coefficient of variation in the errors were summarized and compared after the model extrapolation, and then these characteristic values were compared to analyze the stability of the extrapolation of the three LMC prediction models and the applicability of each model.

\section{Results}

\section{Litter moisture content statistical analysis}

Table 3 shows the basic LMC conditions in eight sample plots. During the fire prevention period, the minimum number of days when the typical LMC in Yunnan was less than 35\% occurred in 
$310 \mathrm{~Pa} 3$, at 67 days, and the maximum occurred in Py2, reaching 85 days. The average LMC of Py1

311

312

313

314

315

316

317

318

319

320

321

322

323

324

325

326

327

328

329

330

331

332

333

334

335

336

337

338

339

340

341

342

343

344

345

346

347

was $20.75 \%$, ranging from $12.83 \%$ to $34.00 \%$. The average LMC of Py 2 was slightly lower than that of Py1, but the range of variation was slightly larger in Py2 than in Py1. For litter of Pinus armandii, the average LMC value and variation range were largest in Pa5; Pa3 was the second largest, and Pa4 was the smallest. The average LMC of Po6 was $21.44 \%$, the minimum was $14.82 \%$, and the maximum was $33.55 \%$. The LMC variation ranges of Py-Pa7 and Py-Pa8 were basically between those of Py and Pa. In the 8 plots, the mean LMC values were, from high to low, Py-Pa8, Po6, Py2, Py1, Py-Pa7, Pa4, Pa3 and Pa5, the minimum LMC value was recorded at Py2, at only $11.41 \%$, and the maximum value was observed in Pa5, at $34.92 \%$.

\section{Correlation analysis}

All LMCs had significant negative correlations with the air temperature, and as the distance from the sampling time increased, the correlation first increased and then decreased. The LMC of Py1 had the weakest correlation with the air temperature; this LMC was only related to the air temperature of the previous 3-7 days, while the LMC of Pa4 had the strongest correlation with air temperature. The average relative humidities of the current day and the previous 6 days were significantly positively correlated with the LMC, and the LMC had the strongest correlation with the average relative humidity of the previous 3 days (Figure 2).

\section{Applicability analysis of the direct use of scale models}

Table 4 shows the $t$-test results for the predicted and measured values after the two scale models were directly used, as well as the model prediction errors. The $t$-test results of the measured LMC values and the values predicted by the FF (FX) scale model for the 8 plots were almost all less than 0.01 , and extremely significant differences existed between the measured and predicted values. For the two scale models, the minimum MAE value was $9.77 \%$, and the maximum was $15.89 \%$. The MRE and RMSE ranges were $47.80 \%-64.53 \%$ and $11.94 \%-19.07 \%$, respectively. The prediction errors were large, and these models cannot be applied in practice. Therefore, it is not applicable to directly use the moisture code method to predict the moisture content of the typical litter in Kunming, Yunnan Province.

\section{Models}

Meteorological elements regression model In the regression models of the 8 sample plots, only the air temperature and relative humidity were selected as predictors. Most of the models selected the air temperature or relative humidity values of the previous day or two days. Only the Pa3 prediction model selected the average temperature of the previous three days as the predictor variable. The variation ranges of the MAE, MRE, and RMSE values of the meteorological element regression models used to predict the LMC in the 8 plots were $2.39 \%-4.39 \%, 10.03 \%$ $23.57 \%$, and $2.98 \%-5.43 \%$, respectively. The MAE of Po6 was the lowest, and the MAE of Py- 
348 pa8 was the highest. The largest deviation between the measured and predicted LMC value was 349 found in Py-pa8, and the smallest was found in Pa4 (Table 4).

350 Moisture code regression model To reduce the variability in the data, natural logarithms were

351

352

353

354

355

356

357

358

359

360

361

362

363

364

365

366

367

368

369

370

371

372

373

374

375

376

377

378

379

380

381

382

383

384

385

386

387

taken for the measured and the predicted values of the scale model based on FF (FX), and a linear model between the two values was established. Table 4 gives the prediction results of the 8 litter moisture contents obtained using the moisture code regression model. No significant difference was observed between the MAE and MRE values obtained by the FF-scale model and the FX-scale model for any litter type ( $t$-test: $\mathrm{p}>0.05)$. The MAE variation range of the moisture content prediction models obtained for the 8 plots based on the FF model was $2.50-5.09 \%$, the minimum MRE was $12.22 \%$, the maximum was $18.61 \%$, and the RMSE variation range was $3.47 \%-6.09 \%$; based on the FX model, the MAE, MRE and RMSE values of the moisture content prediction models varied in ranges of $2.46-5.08 \%, 12.15-18.60 \%$ and $3.45 \%-6.12 \%$, respectively. The $R^{2}$ values of Py2, Po6, and Py-pa8 all exceeded 0.6, explaining the model well, and the prediction errors were smaller in these plots than those of the other plots. The prediction effect of the Pa understory LMC in the three plots obtained using the moisture code method was relatively poor. The MRE had a limit of $15 \%$, and the LMC prediction effects of Pa3 and Pa5 cannot be applied to forest fire risks (Table 4).

Direct estimation model When using the direct estimation method to predict the LMC, the minimum MAE was only $2.16 \%$, and the maximum was 3.64\%. The ranges of MRE and RMSE were $10.69 \%-14.23 \%$ and $2.82 \%-4.29 \%$, respectively. The direct estimation method predicted the model best in Py-pa8, while Pa4 had the worst predictive effect. If the MRE limit is $15 \%$, the LMC prediction results of all plots can be used for fire risk forecasting (Table 4).

\section{Model accuracy comparison}

It can be seen that no significant difference was found in the prediction results of the moisture code regression models based on the FF and FX scale models, and overall, the predictions obtained based on the FF scale model were slightly better than those obtained based on the FX scale model. Therefore, regarding the comparison of prediction methods in this section, only comparisons between the moisture code regression method based on the FF scale model and the other two prediction methods were carried out.

1:1 comparison between measured and predicted values Figure 3 shows a 1:1 comparison of the measured and predicted values of 8 plots based on 3 LMC prediction models. With the exception of the litter in the Py-pa8 plot, in the remaining plots, when the measured LMC value was low, the values predicted by the three prediction models were lower than the measured value. As the measured LMC values increased, the predicted values became higher than the measured values. In almost all plots, the straight line fitted by the direct estimation method was the closest to the $1: 1$ line, followed by that of the multiple regression method of meteorological element; the moisture code was the worst.

Comparison of measured and predicted values For the Py1 and Py2 litters, the direct estimation method and the moisture code regression method predicted value fluctuations that 
388

389

390

391

392

393

394

395

396

397

398

399

400

401

402

403

404

405

406

407

408

409

410

411

412

413

414

415

416

417

418

419

420

421

422

423

424

425

426

427

were close to the actual measured values, and the multiple regression method of meteorological element had a poor prediction effect when the LMC fluctuated frequently. For the litters of Pa3, $\mathrm{Pa} 4$ and $\mathrm{Pa}$, although the predicted values of the three prediction models showed similar fluctuations to the actual measured values to a certain extent, they were all in poor agreement. Among the prediction methods, the direct estimation method had a relatively good prediction effect, followed by the multiple regression method of meteorological element; the moisture code regression model prediction had the worst effect. For the litter of Po6, the predicted values of the three models were in good agreement with the actual measured values. For the Py-pa7 and Pypa8 litters, the direct estimation method obtained the closest fluctuation between the predicted and the measured values, followed by the moisture code regression method, while the multiple regression method of meteorological element was poor (Figure 4).

\section{Model extrapolation ability analysis}

Meteorological element regression model When the meteorological element regression model was extrapolated, the minimum MAE was only $2.52 \%$, consistent with the calculation results of the Po6 litter obtained using the Py2 litter prediction model. The maximum MAE was $8.80 \%$, which appeared in the calculation results of the Py-pa8 prediction model for the Pa5 litter. The mean MAE value extrapolated by the meteorological element regression model was $4.61 \%$, and the mean value of the coefficient of variation $(\mathrm{CV})$ in the MAE was 0.32 . The minimum and maximum MRE values extrapolated by the model were $12.24 \%$ and $51.36 \%$, respectively. The locations of occurrence are the results of the Py1 prediction model for the Py-pa7 litter and the results of the Pa5 prediction model for the Py-pa8 litter. The mean value of MRE extrapolated by the model was $21.99 \%$, and the coefficient of variation was 0.31 (Figure 5).

Moisture content regression model Figure 6 shows the extrapolation of the moisture code model. It can be seen that the minimum extrapolated MAE was $2.55 \%$, and the litter that appeared in Py-pa8 was calculated using the Po6 litter prediction model; the maximum MAE was $8.34 \%$, which appeared in the litter of $\mathrm{Pa} 5$ and was calculated using the Py 2 prediction model. The moisture code model extrapolated the average MAE to $4.11 \%$, and the average coefficient of variation (CV) in the MAE was 0.35 . The minimum and maximum MRE values extrapolated by the moisture code model were $12.17 \%$ and $29.84 \%$, respectively. The locations of occurrence resulted from the $\mathrm{Pa} 4$ prediction model for the $\mathrm{Pa} 4$ litter and from the $\mathrm{Pa} 4$ prediction model for the Pa3 litter. The mean MRE value extrapolated from the model was $18.22 \%$, and the coefficient of variation was 0.27 .

Direct estimation model The minimum MAE obtained when the model was extrapolated was $2.15 \%$, which appeared in the Py-pa8 litter using the Py2 litter prediction model; the maximum MAE was 6.18\%, which appeared in the Pa5 litter using the Py-pa8 prediction model. The direct estimation model extrapolated the average MAE to $3.72 \%$, and the average coefficient of variation $(\mathrm{CV})$ in the MAE was 0.26 . The minimum and maximum MRE values extrapolated by the model were $11.23 \%$ and $30.99 \%$, respectively, and the positions of occurrence are the results of the Py-pa7 litter prediction obtained using the Py1 prediction model and the Py2 litter 
428 prediction obtained using the Py1 prediction model. The mean MRE value extrapolated from the model was $17.19 \%$, and the coefficient of variation was 0.23 (Figure 7).

430

431 Discussion

\section{Difference and correlation analysis of LMC}

433 There are differences in litter moisture content in different sampling areas, the main reason is 434 that due to the different geographical locations (slope, slope direction, etc.), the microclimate 435 conditions of litter are different, which affects the dynamic change of LMC (Samran et al., 1995; 436 Keith et al., 2010). In addition, different types of litter have different physical and chemical

The dynamic changes in the typical litter moisture content in Yunnan Province have certain lags in their responses to all meteorological elements, and with increasing meteorological elements and sampling intervals, the significance first increases and then decreases. The results of this study are the same as those of Pixton and Warburton (Pixton and Warburton, 1971; Britton et al., 1973; Zhang and Sun, 2020). The main reason for this is that the dynamic change of LMC is not completely affected by the meteorological elements of the current day of the previous day, but mainly depends on the degree of its response to the meteorological elements. Therefore, the strongest correlation occurs from the current day to the previous $\mathrm{n}$ days. As the distance from the sampling time exceeds the day with the strongest correlation, the impact of meteorological elements on LMC decrease gradually. Therefore, there will be a significant increase first and then decrease.

The dynamic change of LMC in the study area is significantly negatively correlated with air temperature, and it increases with the increase of relative humidity, which is mainly due to the increase of temperature will improve the ability of air to carry moisture, which will increase the saturation humidity and decrease the relative humidity, the moisture of the litter will diffuse outward, and the LMC will decrease (Alves et al., 2009). The dynamic changes in the LMC of $\mathrm{Pa} 3$ and Pa4 had no significant relationship with wind speed; this result may have been caused by the excessive canopy closure of the two plots and the lower wind speeds in the forests (Holdsworth and Uhl, 1997; Sun et al., 2015). This study only analyzed the situations in which the LMC was lower than $35 \%$, and the dynamic change of LMC is less affected by rainfall. If all the moisture content data are considered, there is a significant correlation between the rainfall and the dynamic changes of LMC $(p<0.001)$. The accumulated rainfall in the first 3-7 days had a significant impact on the dynamic changes in LMC, while the accumulated rainfall in the first 12 days and the same day had no significant impacts, indicating that in the study area, the LMC could be reduced to less than $35 \%$ after 3-7 days of rainfall.

\section{Scale model applicability analysis}

There was a significant difference between the moisture content values obtained by directly using the FF or FX scale models and the LMC values measured in all plots $(\mathrm{P}<0.001)$. The mean error ranges of the 8 plots obtained based on the FF and FX scale models were 5.59\%-14.20\% and $4.30 \%-13.72 \%$, respectively; thus, the models all underestimated the measured values, 
468

469

470

471

472

473

474

475

476

477

478

479

480

481

482

483

484

485

486

487

488

489

490

491

492

493

494

495

496

497

498

499

500

501

502

503

504

505

506

507

similar to the results of Zhang (2018). Anderson (2009) took the gross moisture content as the research object and, based on the FF and FX scale models, obtained MEs of $-11.81 \%$ and $7.52 \%$, respectively. The FF scale model overestimated the measured values, and the FX scale model underestimated the measured values; these results may have been related to the LMC interval studied. In this study, only moisture contents below 35\% were selected. During the study period, there was almost no rainfall, and the water loss rate under rainfall conditions in the scale model was not applicable and would cause the LMC values to be overestimated (Zhang et al., 2017). Therefore, the results of the two studies were different. Many studies have shown that direct use of the FFMC scale model is not applicable for LMC predictions, mainly due to the large gap between the litter type or stand structure and the actual situation at the sample site in the initial scale model study (Chrosciewicz, 1989; Abbott et al., 2007). For example, the scale model is obtained based on a study on litters with a thickness of $1.2 \mathrm{~cm}$, while the thicknesses of the litters in most sample areas examined in this study were above $3.0 \mathrm{~cm}$. In addition, the key parameters that represent set values such as the equilibrium moisture content and time lag in the model cause great errors when compared with the actual situation; thus, this model it cannot be directly used.

\section{Model predictors and parameters}

In the meteorological element regression model, the predictive factors are the same among the same litter type and different places, indicating that the LMC response to meteorological elements is better than the response to forest stand conditions due to the influence of the litter type. Except for the $\mathrm{Pa}$ litter, relative humidity was the predictor for all the other LMC meteorological element models; this result further proves that relative humidity has the greatest influence on dynamic changes in the LMC (Pixton and Warburton, 1971; Jiménez et al., 2016). The stepwise regression method is selected to establish the multiple regression model of meteorological elements, the most important variables are selected from a large number of selectable meteorological element as the predictor variable of the model, which avoids the collinearity between meteorological elements. Therefore, some litter prediction models choose relative humidity, and some are temperature, but they are essentially multiple regression models of meteorological elements of LMC, so they are comparable to each other.

The parameters $\alpha$ and $\beta$ of the FF moisture code regression models of the 8 plots ranged from 7.21-12.55 and from 0.25-0.39, respectively; in the FX moisture code regression model, these parameters ranged from 7.40-12.76 and from $0.25-0.37$, respectively. The $\alpha$ values (1.9893 and 4.6381) in the FF and FX moisture code regression models obtained by Anderson were lower than those obtained in this study, and the $\beta$ values $(0.6545$ and 0.5868$)$ of Anderson were higher than those obtained in this study (Anderson and Anderson, 2009). This is mainly because the LMC data selected for analysis in this study had values less than $35 \%$, while Anderson used all LMC data.

The minimum value of the parameter $\alpha$ in the LMC prediction model of the direct estimation method was 6.72, and the maximum value was 37.70. The results of Catchpole et al.'s study found that the range of $\alpha$ was $0.26-0.37$ (Catchpole et al., 2001). Sun (2015) classified typical Daxinganling forests as the research objects, and the results showed that the range of $\alpha$ changed 
508 from 0.087-0.594. Zhang and Sun (2020) took Quercus mongolica and Korean pine litter as the

509

510

511

512

513

514

515

516

517

518

519

520

521

522

523

524

525

526

527

528

529

530

531

532

533

534

535

536

537

538

539

540

541

542

543

544

545

546

547

research objects and obtained $\alpha$ values of 0.25 and 0.004 , respectively. The results of this study were significantly higher than those of other scholars, mainly due to the different research step lengths used. The monitoring step length of this study was $24 \mathrm{~h}$. If the monitoring step length increased, $\alpha$ would increase to a certain extent. The absolute value of $\beta$ in the Nelson model represents the response degrees of dynamic changes in the LMC to environmental elements. A larger absolute value of $\beta$ indicates a more sensitive responses of dynamic changes in the LMC to environmental elements (Nelson and Ralph, 1984). For the same type of litter, the absolute value of $\beta$ in the LMC prediction model is higher for sunny slopes than for shaded slopes. This is similar to the results of Sun et al (2015). The dynamic changes in the LMC observed on sunny slopes are more sensitive to the response of meteorological elements than those observed on shaded slopes. Because the physical and chemical properties of litter and the bed structure have significant effects on dynamic changes in the LMC, the $\beta$ values differ among different litters.

\section{Time lag of litter bed}

The direct estimation method shows that the time lag of the litter beds in 8 plots ranged from 10.42-27.45 h; these values were higher than those reported in the results of Catchpole et al (2001). Because of the different physical and chemical properties of litter, the water diffusion rates also differ. In addition, these results are also related to experimental methods. Catchpole spread litters on the land surface, and water vapor exchange occurred almost exclusively between the litter and the external environment. The research object of this paper was the litter bed, and the moisture change rate was analyzed in addition to the responses of the litters to the external environments; these factors were also related to the internal structure of the litter bed and the water vapor exchange between the litter and the litter in the bed (Liu, 2007; Ruiz et al., 2009; Jin and Chen, 2011). The average thickness of the litter beds examined in this study was $3.5 \mathrm{~cm}$, which was higher than those analyzed other studies. Therefore, the change rate of water obtained in this study was lower than that of Catchpole et al (2001) with a higher time lag.

\section{Model accuracy analysis}

The mean MAE and MRE values of the multiple regression methods of meteorological element applied for the 8 sample plots in this study were $2.97 \%$ and $14.06 \%$, respectively. Lu et al (2016) used the typical litter in the Nanweng River as the research object and established a regression model of meteorological elements. The minimum MAE and MRE values of their model were as high as $18.9 \%$ and $27.7 \%$, respectively; these values were significantly higher than those obtained in this study. The main reason for this discrepancy is that this study only conducted research on data in which the LMC values were below $35 \%$, and more predictive factors were considered entering the models, making the models more comprehensive. Therefore, the regression model error of the meteorological elements with a daily step size was lower. Sun et al (2015) took the typical litter in the Daxinganling Mountains as the research object and obtained MAE and MRE values of the LMC meteorological element regression model of $1.48 \%$ and $9.01 \%$, respectively. Zhang and Sun (2020) obtained LMC meteorological element regression model errors of Quercus mongolica and Korean pine of $1.95 \%$ and $13.26 \%$, respectively. The 
548 model errors obtained in these studies were slightly lower than those obtained in this study,

549

550

551

552

553

554

555

556

557

558

559

560

561

562

563

564

565

566

567

568

569

570

571

572

573

574

575

576

577

578

579

580

581

582

583

584

585

586

587

mainly due to the different research steps; the previous studies all used hours as the step length.

The mean MAE of LMC values obtained from the moisture code regression models based on the FF and FX scale models for the 8 plots were $3.27 \%$ and $3.26 \%$, respectively, and the MRE means were $14.04 \%$ and $14.07 \%$, respectively; these values were similar to the research results of Anderson et al (2009). The prediction error of the scale regression model was higher than that of the meteorological element regression model. This may be because the scale model itself was not applicable, and its built-in equilibrium moisture content, time lag and other key parameter models were also not applicable to the typical litter in Yunnan (Anderson and Anderson, 2010; Zhang, 2018). In this study, the litter bed structure, physical and chemical properties, geographical conditions and climate zone were significantly different from the FWI system study area and litter types, so this model may not be applicable (Abbott et al., 2007; Schiks and Wotton, 2014).

The mean MAE and MRE values of the LMC prediction models of the 8 plots obtained by the direct estimation method were $2.82 \%$ and $12.76 \%$, respectively. These results are lower than those reported in the study of Lu et al (2016). Although the study step was the same between these two studies, this study only considered LMC data with values less than $35 \%$ instead of rainfall data, thus improving the prediction accuracy, so the prediction accuracy of this study was higher than the results of Lu et al. Catchpole et al. chose the direct estimation method to obtain MAEs of the LMC prediction model with a range of $0.8 \%-1.9 \%$. The MAEs of Quercus mongolica and Pinus koraiensis obtained by Zhang and Sun (2020) were $1.02 \%$ and $4.73 \%$, respectively. The prediction effects were better than in their study than those obtained this study, which was also caused by the prediction step.

Through the $t$-test, no significant difference was observed among the MAEs (MREs) of the three LMC prediction methods, but the direct estimation method had the lowest error and the best prediction effect.

\section{Model extrapolation ability analysis}

The extrapolated average MAEs of the multiple regression method of meteorological element, scale model regression method and direct estimation method were $4.61 \%, 4.11 \%$ and $3.72 \%$, respectively, and the MREs were $21.99 \%, 18.22 \%$ and $17.19 \%$, respectively. The extrapolation error of the multiple regression method of meteorological element was significantly higher than those of the other two methods, while the moisture code regression method and the direct estimation method had no significant difference. In addition, the direct estimation method had the smallest mean coefficient of variation value, at only 0.26 , which was lower than those of the other two methods. Therefore, the best extrapolation effect was the direct estimation method, followed by the moisture code regression method, while the worst was the multiple regression method of meteorological element; these results are consistent with the research results of Yu et al (2013a; 2013b). Consistent with the results reported in section model accuracy analysis, because the equilibrium moisture content and time lag model were not corrected in the FFMC, the moisture code regression method was not applicable for predicting the litter moisture content in this area, and the prediction error was large. The LMC prediction model obtained by the

Peer) reviewing PDF | (2021:05:61265:2:0:NEW 24 Aug 2021) 
588 multiple regression method of meteorological element had a poor extrapolation ability, and some

589

590

591

592

593

594

595

596

597

598

599

600

601

602

603

604

605

606

607

608

609

610

611

612

613

614

615

616

617

618

619

620

621

\section{2}

623

624

625

626

627

extrapolated MREs were as high as $50 \%$ or more; this model cannot meet the daily fire risk forecast demand. The direct estimation method can be used to predict the typical LMC in Yunnan Province, and the predictive ability and extrapolation ability of this method can fully meet the daily fire risk forecast demand.

\section{Conclusions}

The results showed that the dynamic change in the typical litter moisture content in Yunnan Province had an obvious lag under different stand conditions; these variations were mainly related to the air temperature, humidity and wind speed. With an increase in meteorological elements and the sampling interval, the significance first increased and then decreased. Direct use of the scale model for LMC predictions was not applicable because there was a significant difference between the predicted and the measured values. Although the prediction model obtained by the regression had a good extrapolation ability, it also had a large error. The prediction error of the multiple regression method of meteorological element was also large, and its extrapolation ability was poor. Therefore, neither of these two methods could meet the daily fire risk forecast accuracy requirements of the study area. The prediction accuracy and extrapolation ability of the direct estimation method obtained based on the Nelson equilibrium moisture content equation could meet the daily fire risk forecast in this area.

The research on the dynamic changes in LMC and the prediction models conducted in this study aimed to lay a foundation for local daily fire risk forecast research. If the LMC prediction values are applied to predict fire behaviors, the accuracy of this research would not be satisfied, and it would be necessary to further shorten the LMC research scale and improve the forecast accuracy. This study also has some limitations. For example, the litter bed structure, especially the litter bed density and composition, has a certain impact on the dynamic changes in the LMC and on the prediction results. In addition, the selection of the equilibrium moisture content equation in the direct estimation method also impacts the prediction results, and this study did not consider the dynamic changes of LMC under extreme climates. In future research, the litter bed structure should be considered comprehensively, the research step length should be shortened, the influence of extreme climates on the LMC needs to be considered and more prediction methods of LMC also need to be considered (Matthews, 2014; Resco et al., 2015). These advancements will provide great significance for understanding the dynamic change mechanism of the LMC and for improving fire prediction accuracy.

\section{Acknowledgements}

This research was funded by the Natural Science Foundation of Guizhou Province grant number ZK[2021] general 158 and the Guizhou provincial first-class major (biological science) project (Education department of guizhou province [2019] 46. We are indebted to the graduate students Yong Zhou, Jinbo Liu for their support in field work. We are also grateful to two anonymous reviewers for their valuable comments. 
628

\section{9}

630

631

632

633

634

635

636

637

638

639

640

641

642

643

644

645

646

647

648

649

650

651

652

653

654

655

656

657

658

659

660

661

662

663

664

665 666

\section{References}

Abbott KN, Alexander ME, Maclean DA, Brigitte L, Judith AB, Gordon CS (2007) Predicting forest floor moisture for burned and unburned Pinus banksiana forests in the Canadian Northwest Territories. International Journal of Wildland Fire 16(1), 71-80.

Alves MVG, Batista AC, Soares RV, Ottaviano M, Marchetti M (2009) Fuel moisture sampling and modeling in Pinus elliottii Engelm. Plantations based on weather conditions in Parana, Brazil. iForest-Biogeosciences and Forestry 2, 99-103.

Anederson HE, Schuette RD, Mutch R W (1978) Timelag and equilibrium moisture content of ponderosa pine needles. United States Department of Agriculture (INT-202), 1-25.

Anderson SAJ, Anderson WR (2009) Predicting the elevated dead fine fuel moisture content in gorse (Ulex europaeus L.) shrub fuels. Canadian Journal of Forest Research, 39(12), 23552368.

Anderson SAJ, Anderson WR (2010) Ignition and fire spread thresholds in gorse (Ulex europaeus). International Journal of Wildland Fire 19(5), 589-598.

Anon (2012) Next generation forecast and warning system. Australian Government Bureau of Meterorology, Technical Report. (Melbourne)

Bradshaw LS, Deeming JE, Burgan RE, et al (1984) The 1978 national fire-danger rating system: technical documentation. USDA Forest Service General Technical Report, (INT169), 1-41.

Britton CM, Countryman CM, Wright HA, Walvekar AG (1973) The Effect of Humidity, Air Temperature, and Wind Speed on Fine Fuel Moisture Content. Fire Technology 9, 46-55.

Byram GM, Jemison GM (1943) Solar radiation and forest fuel moisture. Journal of Agricultural Research 67(4), 149-176.

Byram GM, Nelson RM (1963) An Analysis of the drying Process in Forest Fuel Material. In General Technical Report; Southern Research Station, USDA Forest Service: Blacksburg, VA, USA, 1-38.

Catchpole EA, Catchpole WR, Viney NR, McCaw WL, Marsden-Smedley JB (2001) Estimating Fuel Response Time and Predicting Fuel Moisture Content From Field Data. International Journal of Wildland Fire 10(2), 215-222.

Chrosciewicz Z (1989) Prediction of forest-floor moisture content under diverse jack pine ca. Canadian Journal of Forest Research 19(19), 1483-1487.

Chuvieco E, Agiado I, Dimitrakopoulos AP (2004) Conversion of fuel moisture content values to ignition potential for integrated fire danger assessment. Canadian Journal of Forest Research 34(11), 2284-2293.

Deeming JE, Brown JK (1975) Fuel Models in the National Fire-Danger Rating System. Journal of Forestry Washington 73(6), 347-350.

Fiorucci P, Gaetani F, Minciardi R (2008) Development and application of a system for dynamic wildfire risk assessment in Italy. Environmental Modelling \& Software 23, 690-702. 
667 Glahn H, Ruth D (2003) The new digital forecast database of the national weather service.

668 Bulletin of the American Meteorological Society 84, 195-201.Holden ZA, Jolly WM (2012)

669 Modeling topographic influences on fuel moisture and fire danger in complex terrain to

670 improve wildland fire management decision support. Forest Ecology and Management

$671 \quad$ 262(12), 2133-2141.

672 Holdsworth A, Uhl C (1997) Fire in Amazonian selectively logged rain forest and the potential

673 for fire reduction. Ecological Applications 7, 713-725.

674 Jin S, Chen P (2012) Modelling drying processes of fuelbeds of Scots pine needles with initial

675 moisture content above the fibre saturation point by two-phase models. International

$676 \quad$ Journal of Wildland Fire 21(4), 418.

677

678

Jin S, Yan XJ (2012) Dynamics and modeling of water content of ten shrub species in their

679 growth period in Maoershan Mountain region of Northeast China. Chinese Journal of Applied Ecology 23(12), 3317-3324.

680

681

682

Kandya AK, Kimothi MM, Jadhav RN, Agarwal JP (1998) Application of Geographic Information System in Identification of 'Fire-prone' Areas-A Feasibility Study in Parts of Junagadh (Gujarat). Indian Forester 124(7), 531-535.

683

Keith DM, Johnson EA, Valeo C (2010) A hillslope forest floor (duff) water budget and the

684 transition to local control. Hydrological Processes 24, 2738-2751.

685

King A, Linton M (1963) Report on moisture variation in forest fuels: equilibrium moisture content. CSIRO Division of Physical Chemistry, Technical Report. (Melbourne).

687

Liu X (2007) Effects of Temperature and Humidity on Fuel Equilibrium Moisture Content. MSc

688 thesis, Northeast Forestry University, Harbin, China.

689

Luke RH, Mcarthur AG (1978) Bush Fires in Australia. European Journal of Surgical Oncology

690 22(4), 354-358.

691

Lu X (2016) Research on Dynamic and Prediction Model of Dead Fuel Moisture Content of

692

693 Typical Stands in Great Xing' an Mountains. Doctoral Thesis, Northeast Forestry

694 University, Harbin, China.

Nelson JR, Ralph M (1984) A Method for Describing Equilibrium Moisture Content of Forest

696 Fuels. Canadian Journal of Forest Research 14(4), 597-600.

697

698

699

700

701

702

703

704

705

Nolan RH, Resco de D, Boer MM, et al (2016) Predicting dead fine fuel moisture at regional scales using vapour pressure deficit from MODIS and gridded weather data. Remote Sensing of Environment. 174, 100-108.

Matthews S, Mccaw WL (2006) A Next-generation Fuel Moisture Content Model For Fire Behavior Prediction. Forest Ecology \& Management 234, s27-30.

Matthews S, Mccaw WL, Neal JE, Smith RH (2007) Testing a Process-based Fine Fuel Moisture Model in Two Forest Types. Canadian Journal of Forest Research 37(1), 23-35.

Matthews S, Gould J, McCaw L (2010) Simple models for predicting dead fuel moisture in eucalyptus forests. International Journal of Wildland Fire 19, 459-467.

Matthews S. (2014) Dead fuel moisture research: 1991-2012. International Journal of Wildland

706 Fire 23, 78-92. 
707 Pech GY (1989) A model to predict the moisture content of reindeer lichen. Forest Science 708 35(4): 1014-1028.

709 Pixton SW, Warburton S (1971) Moisture Content/Relative Humidity Equilibrium of Some

710 Cereal Grains at Different Temperatures. Journal of Stored Products Research 6, 283-293.

711 Pook EW, Gill AM (1993) Variation of live and dead fine fuel moisture in Pinus radiata

712 plantations of the Australian-Capital-territory. International Journal of Wildland Fire 3(3), 713 155-168.

714 Resco de Dios V, Fellows AW, Nolan RH, et al 2015. A semi-mechanistic model for predicting 715 the moisture content of fine litter. Agricultural and Forest Meteorology 203: 64-73.

716 Ruiz AD, Maseda CM, Lourido C, Viegas DX (2002) Possibilities of Dead Fine Fuels Moisture 717 Prediction in Pinus Pinaster Ait. Stands at "Cordal de Ferreiros" (Lugo, north-western of

718 Spain). Forest Fire Research \& Wildland Fire Safety: IV International Conference on Forest $719 \quad$ Fire Research Wildland Fire Safety Summit.

720

721

722

723

724

725

726

727

728

729

730

731

732

733

734

735

736

737

738

739

740

741

742

743

744

745

Ruiz AD, Vega JA, Álvarez JG (2009) Construction of Empirical Models for Predicting Pinus sp. Dead Fine Fuel Moisture in NW Spain. I: Response to Changes in Temperature and Relative Humidity. International Journal of Wildland Fire 18(1), 71-83.

Samran S, Woodard PM, Rothwell RL (1995) The effect of soil-water on ground fuel availability. Forest Science 41, 255-267.

Schiks TJ, Wotton BM (2014) Modifying the Canadian Fine Fuel Moisture Code for masticated surface fuels. International Journal of Wildland Fire 24(1), 79.

Simard AJ, Eenigenburg JE, Blank RW (1984) Predicting Fuel Moisture in Jack Pine Slash: a test of two systems. Canadian Journal of Forest Research 14(1), 68-76.

Slijepcevic CA, Anderson WR, Matthews S (2013) Testing existing models for predicting hourly variation in fine fuel moisture in Eucalypt forests. Forest Ecology and Management 306, 202-215.

Sun P, Yu HZ, Jin S (2015) Predicting hourly litter moisture content of larch stands in daxinganling region, China using three vapour-exchange methods. International Journal of Wildland Fire 24, 114-119.

Toomey M, Vierling LA (2005) Multispectral remote sensing of landscape level foliar moisture: techniques and applications for forest ecosystem monitoring. Canadian Journal of Forest Research 35(5), 1087-1097.

Viney NR, Hatton TJ (1989) Assessment of existing fine fuel moisture models applied to Eucalyptus litter. Australian Forestry 52(2), 82-93.

Wagner CEV (1977) A Method of Computing Fine Fuel Moisture Content Throughout the Diurnal Cycle.

Wagner CEV (1979) A laboratory study of weather effects on the drying rate of jack pine litter. Canadian Journal of Forest Research 9(2), 267-275.

Wotton BM, Beverly JL (2007) Stand-specific litter moisture content calibrations for the Canadian Fine Fuel Moisture Code. International Journal of Wildland Fire 16(4), 463-472. 
746 Wotton B (2009) A grass moisture model for the Canadian Forest Fire Danger Rating System. In

747 'Eighth Symposium on Fire and Forest Meteorology', 13-15 October 2009, Kalispell, MT.

748 (American Meteorological Society: Boston, MA)

749 Yu HZ, Jin S, Di XY (2013) Prediction Models for Ground Surface Fuels Moisture Content of

750 Larix gmelinii Stand in Daxing'anling of China Based on One-hour Time Step. Chinese

751 Journal of Applied Ecology 24(6), 1565-1571.

752 Yu HZ, Jin S, Di XY (2013) Models for Predicting the Hourly Fuel Moisture Content on the

753

754

755

756

757

758

759

760

761

762

763

764

765

766 Forest Floor of Birch Stands in Tahe Forestry Bureau. Scientia Silvae Sinicae 49(12), 108113.

Zhang JL, Cui XY, Wei R, et al (2017) Evaluating the applicability of predicting dead fine fuel moisture based on the hourly fine fuel moisture code in the South-eastern Great Xina'an Mountains of China. International Journal of Wildland Fire 26(2), 167-175

Zhang JL (2018) Study on the fuel moisture codes and dynamic of fuel moisture content in Jiagedaqi and Fuyuan. Doctor Thesis, Northeast Forestry University, Harbin, China.

Zhang YL, Guo Y, Hu HQ (2021) Characteristics of Forest Fire Data in Southwest China during 2001-2007. Journal of Northwest Forestry University, 36(1), 179-186.

Zhang YL, Sun P, Hu HQ, et al (2018) Laboratory study of the effects of wind speed on drying coefficient of fuelbeds composed of Korean pine needles with varied structure. Journal of Central South University of Forestry \& Technology 38(3), 51-58.

Zhang YL, Sun P (2020) Study on the Diurnal Dynamic Changes and Prediction Models of the Moisture Contents of Two Litters. Forests, 11(1), 95. 


\section{Table $\mathbf{1}$ (on next page)}

Table 1 The information of plot

To make the descriptions more concise, Pinus yunnanensis, Pinus armandii, Platycladus orientalis and Pinus yunnanensis - Pinus armandii are abbreviated as Py, Pa, Po and Py-pa, respectively. Sample plots 1 through 8 are hereafter denoted as Py1, Py2, Pa3, Pa4, Pa5, Po6, Py-pa7 and Py-pa8. 


\begin{tabular}{cccccccc}
\hline Plot & Forest type & Exposure & $\begin{array}{c}\text { Slope } \\
\left({ }^{\circ}\right)\end{array}$ & Location & $\begin{array}{c}\text { Depth of } \\
\text { fuel }(\mathrm{cm})\end{array}$ & $\begin{array}{c}\text { Fuel load } \\
\left(\mathrm{t} \cdot \mathrm{ha}^{-1}\right)\end{array}$ & $\begin{array}{c}\text { Canopy } \\
\text { density }\end{array}$ \\
\hline 1 & Py1 & Semisouth & 10 & Upper & 3.9 & 2.83 & 0.5 \\
2 & Py2 & South & 10 & Upper & 4.4 & 3.38 & 0.6 \\
3 & Pa3 & North & 35 & Upper & 2.4 & 2.11 & 0.7 \\
4 & Pa4 & South & 0 & Mid & 3.7 & 3.46 & 0.8 \\
5 & Pa5 & South & 10 & Mid & 4.8 & 3.64 & 0.4 \\
6 & Po6 & Semisouth & 30 & Mid & 1.6 & 4.81 & 0.8 \\
7 & Py-pa7 & Seminorth & 20 & Upper & 3.4 & 4.62 & 0.5 \\
8 & Py-pa8 & South & 25 & Mid & 3.5 & 4.22 & 0.4 \\
\hline
\end{tabular}

1 
Table 2 (on next page)

Table 2 Basic Overview of Meteorological Elements 


\begin{tabular}{ccccc}
\hline & Temperature $\left({ }^{\circ} \mathrm{C}\right)$ & Relative humidity $(\%)$ & Wind speed $\left(\mathrm{m} \cdot \mathrm{s}^{-1}\right)$ & Rainfall $(\mathrm{mm})$ \\
\hline Mean & 22.74 & 37.18 & 2.78 & 1.34 \\
Medium & 21.96 & 31.30 & 1.80 & 0.00 \\
Max & 32.33 & 92.30 & 9.97 & 42.81 \\
Min & 8.77 & 14.70 & 0.00 & 0.00 \\
\hline
\end{tabular}

1 


\section{Table 3 (on next page)}

Table 3. Basic information on the moisture contents of the litters in the eight sample plots 


\begin{tabular}{cccccccc}
\hline $\begin{array}{c}\text { Forest } \\
\text { type }\end{array}$ & $\mathrm{N}$ & Mean & Minimum & Maximum & $\begin{array}{c}\text { Percentile } \\
25\end{array}$ & $\begin{array}{c}\text { Percentile } \\
75\end{array}$ & Std. \\
\hline Py1 & 82 & 20.75187 & 12.83160 & 34.00336 & 16.94826 & 23.18630 & 4.657846 \\
Py2 & 85 & 19.47853 & 11.40590 & 34.26783 & 15.76367 & 21.31457 & 5.354328 \\
Pa3 & 67 & 24.62457 & 17.79000 & 33.97879 & 21.28038 & 26.63266 & 4.055139 \\
Pa4 & 74 & 24.18342 & 17.30228 & 32.53193 & 20.86533 & 27.07264 & 4.073415 \\
Pa5 & 73 & 25.80851 & 15.64700 & 34.92262 & 20.62256 & 30.32734 & 5.590288 \\
Po6 & 81 & 19.94026 & 12.70799 & 34.68168 & 16.65793 & 22.74278 & 4.672823 \\
Py-pa7 & 79 & 21.43997 & 14.81812 & 33.54526 & 18.45807 & 23.69726 & 4.181648 \\
Py-pa8 & 84 & 19.09674 & 11.96713 & 31.30165 & 16.13363 & 21.50934 & 4.216814 \\
\hline
\end{tabular}

1 


\section{Table 4 (on next page)}

Table 4 Estimated parameters and errors of all the models established directly using the moisture code and three different methods 


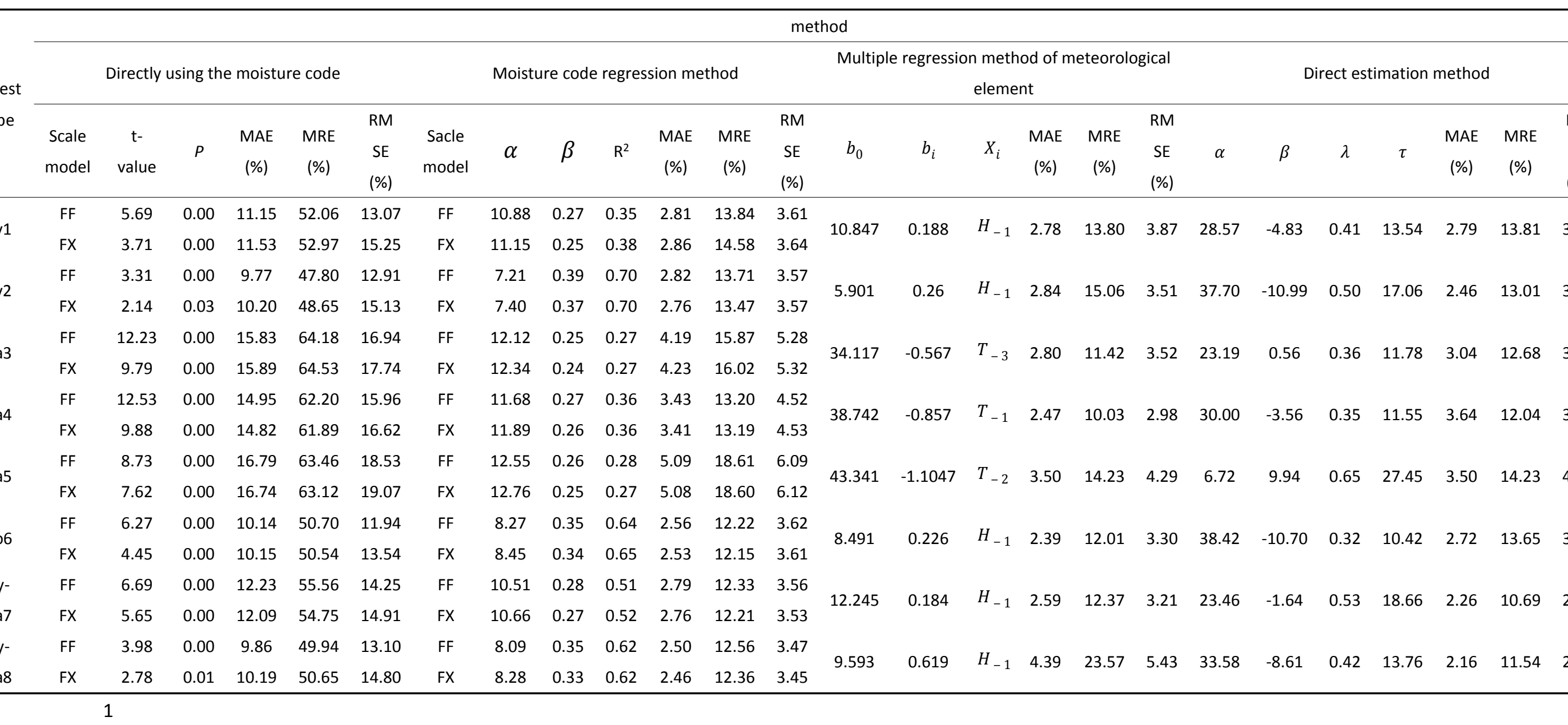


Figure 1

Figure 1 Overview map of the study area
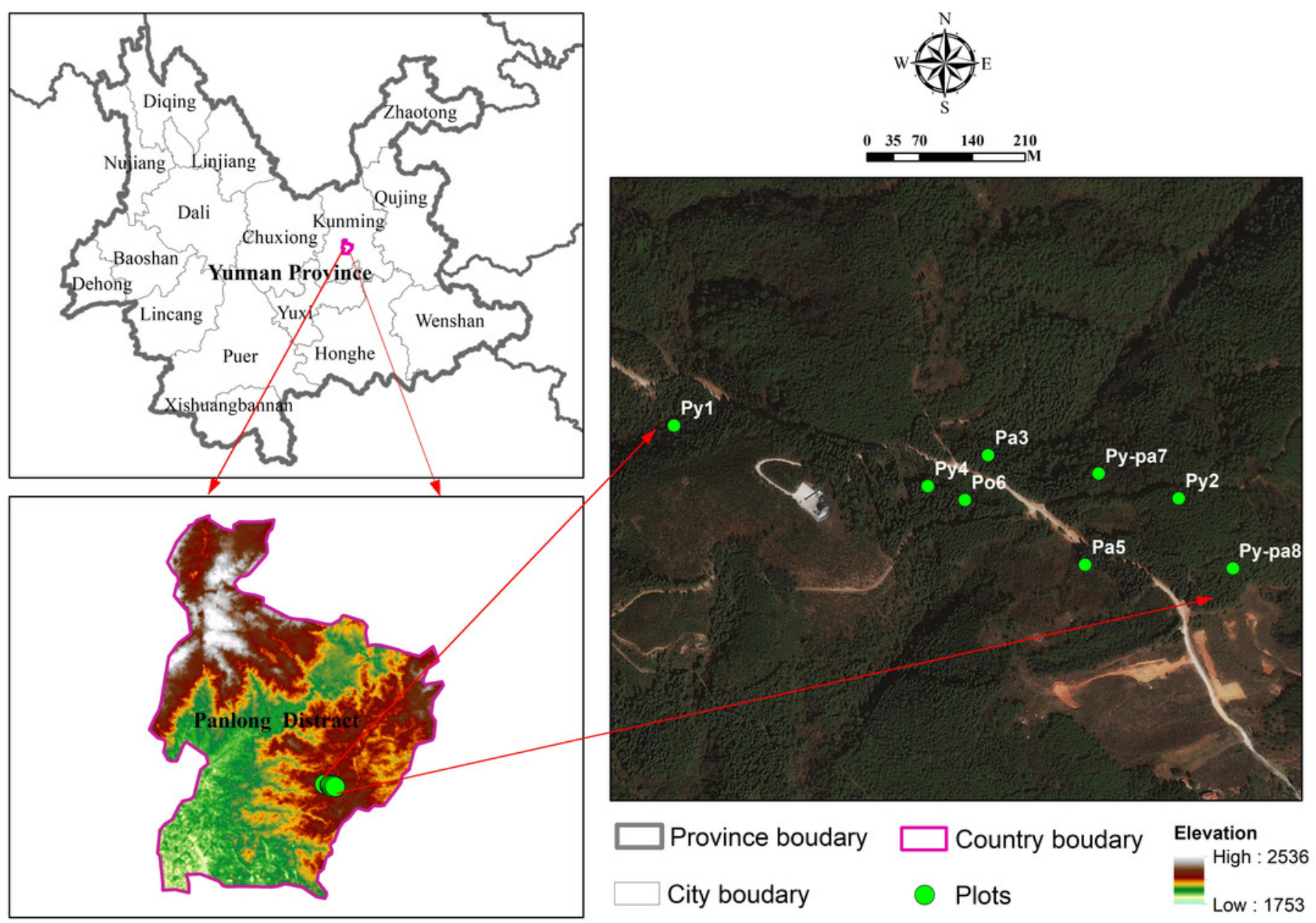
Figure 2

Figure 2 Correlation coefficient between dynamic changes in the LMC and the meteorological factors of the last $n$ days

Note: The red areas indicate that the LMC was significantly related to the meteorological factors at 0.05 level.




Figure 3

Figure 3 Comparison between measured and predicted values
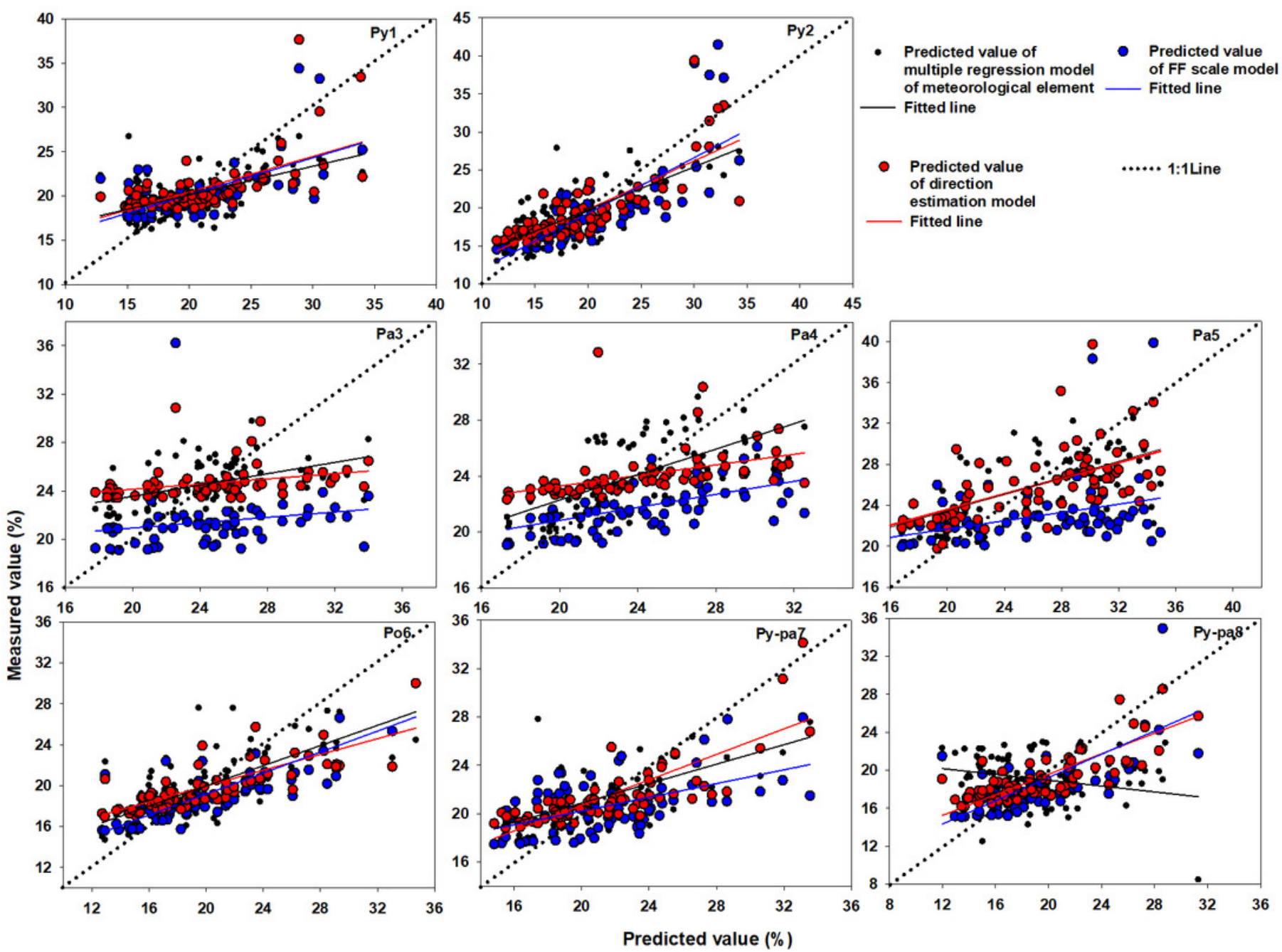
Figure 4

Figure 4 Comparison of the measured and predicted value fluctuations during the monitoring period 


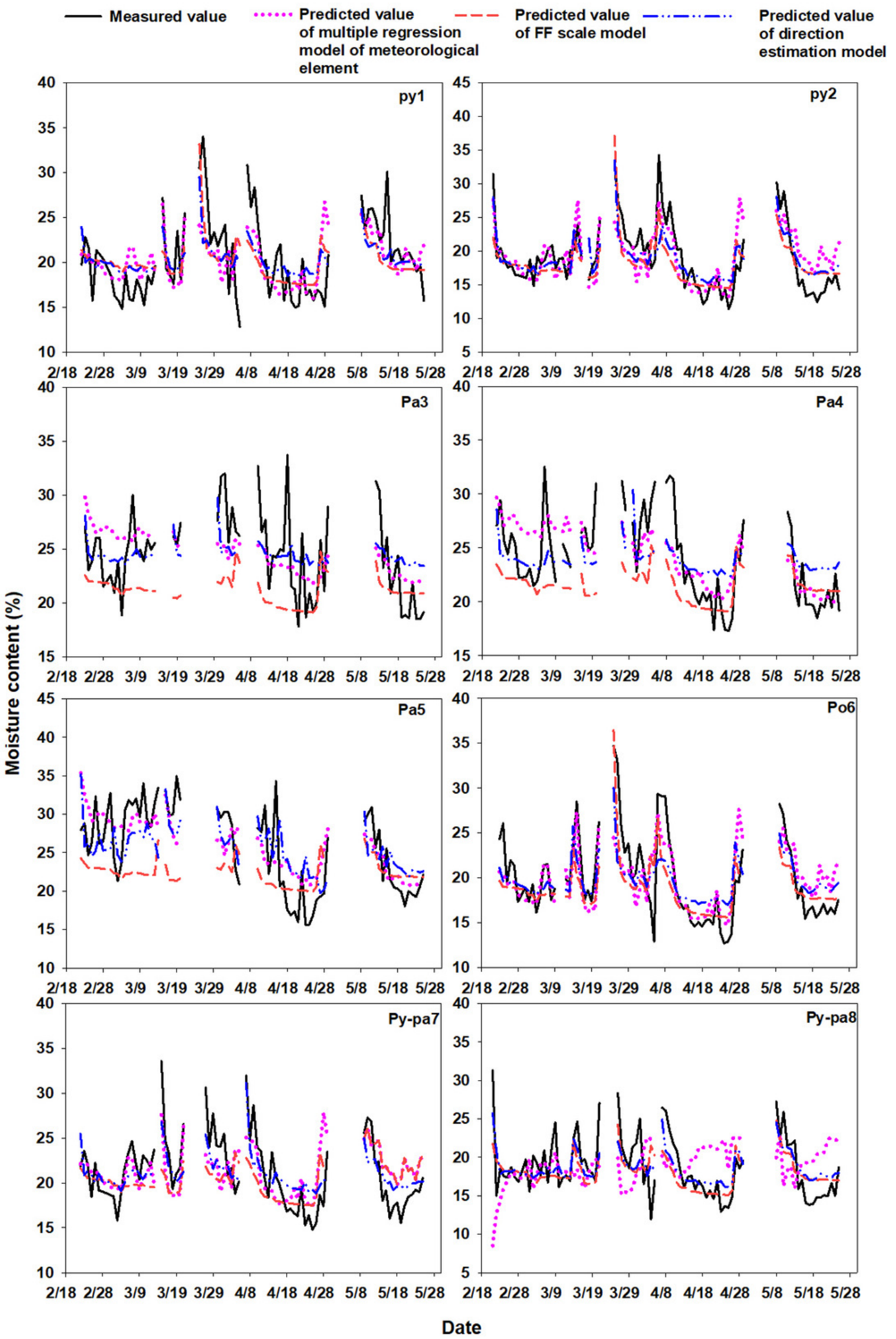


Figure 5

Figure 5 Multiple regression model of meteorological element extrapolation errors and coefficient of variance in the eight plots
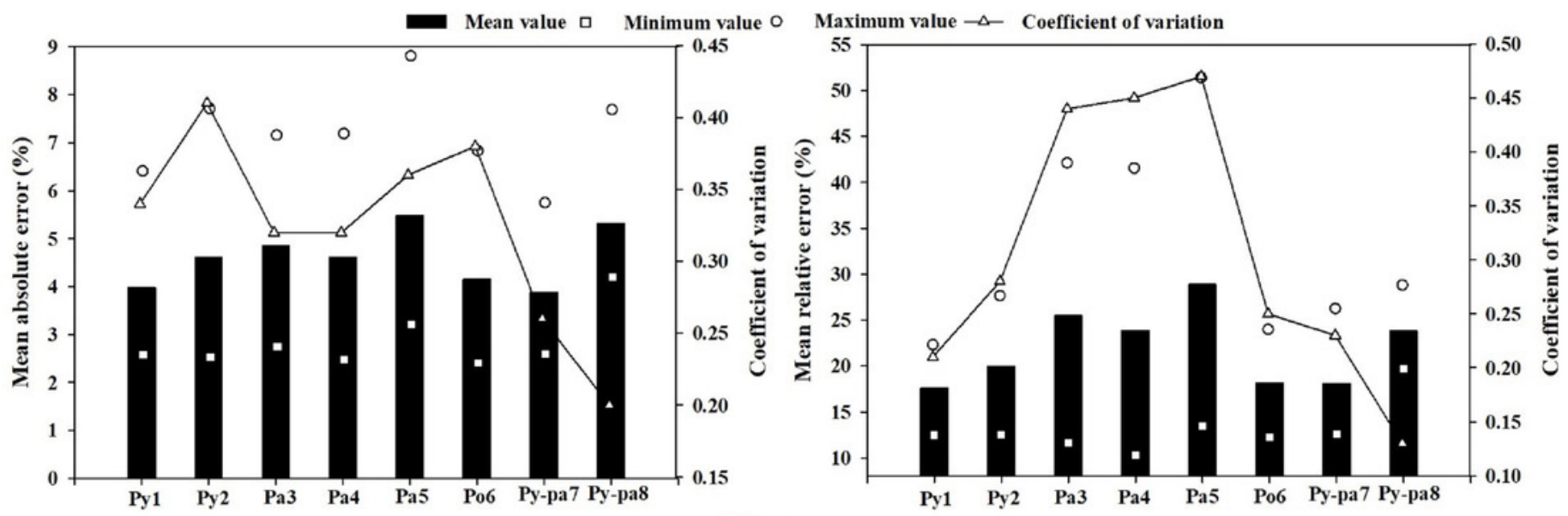

Litter type 
Figure 6

Figure 6 Moisture code regression model extrapolation errors and coefficient of variance in the eight plots

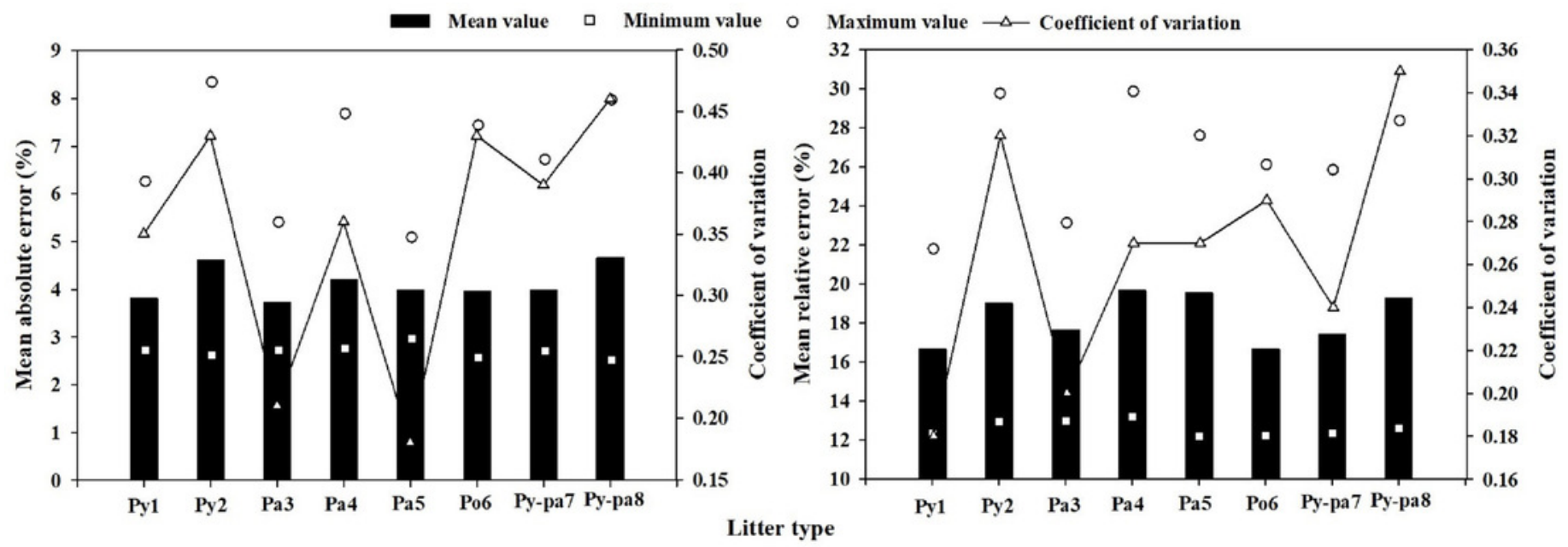


Figure 7

Figure 7 Direct estimation model extrapolation errors and coefficient of variance in the eight plots
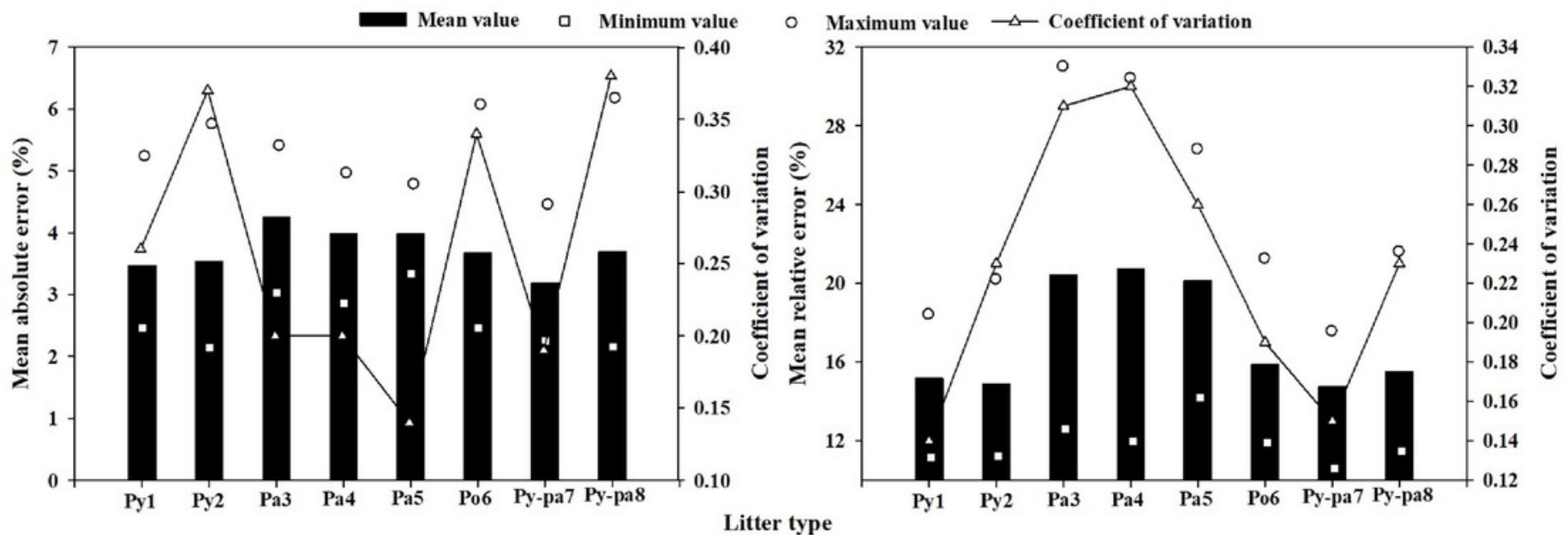